\title{
Natural Gas Exploration Using Carbon Isotopic Fractionation Effect: A Case Study of Shanxi Formation, Upper Palaeozoic Group in the Center of Ordos Basin, China
}

\author{
Yun-Feng Zhang
}

\begin{abstract}
Carbon isotopic fractionation would occur during the process of natural gas generation and migration. As for 'self-generating and self-preserving' tight sandstone gas reservoir, carbon isotope better keeps the current maturity and migration results. In this paper, three local hydrocarbon generation centers and two relatively lower permeability zones were determined from the study area and it is suggested that natural gas migrated roughly from south to north direction through the analysis of carbon isotope isoline. Thus, we predict three favorable exploration areas using natural gas storage index combined with above isotopic results.
\end{abstract}

Index Terms-Carbon isotopic fractionation, natural gas exploration, Ordos basin, upper palaeozoic.

\section{INTRODUCTION}

It is a common geochemistry phenomenon that carbon isotopic fractionation would occur during the process of natural gas generation and migration. Carbon isotope becomes heavier as organic matter of the gas source rock becomes more mature; meanwhile, carbon isotope appears lighter along the direction of natural gas migration. Therefore natural gas carbon isotope records parent material source, and information of geology and geochemistry action that parent material and its products experience. Researchers in China and other countries have found and confirmed fractionation effect of natural gas carbon isotope, and built quantitative relations of $\delta 13 \mathrm{C} 1$ and Ro that suggested specific mathematical relationship for the different type of source rocks. It is verified by indoor research that carbon isotopic fractionation range is wide under low temperature, and hydrocarbons that organic matter discharges contain lighter carbon isotope; as the temperature rises, fractionation effect is reduced, and carbon isotope of generated compounds become heavier[1],[2]. It is also concluded by indoor experiments that natural gas always displays carbon isotopic fractionation effect to a different extent when it is injected into and diffuses through several types of lower permeability rocks respectively, in which montmorillonitic clay is the most obvious, kaolinitic clay takes the second and limestone fractionation effect is the least[3]-[6].

Moreover, gas isotopic fractionation is influenced by migration dimension and channel. When natural gas flows in bulk through reservoir rocks, carbon isotopic fractionation is not obvious as the gas-rock medium contract area is small

Manuscript received January 5, 2013; revised February 27, 2013

Yun-feng Zhang is with School of Energy Resources, China University of Geosciences, Beijing 100083 China (e-mail: zh_zyf@ sina.com). and the dwelling time is short; whereas the gas is seeping through the rocks with a smaller scale and slower flow rate, the fractionation is strong because of the long dwelling time and the adequate gas-rock contract, that leads carbon isotope along front of migration direction becomes light.

As a result, an application of carbon isotope information is to infer the direction of natural gas migration and the possible enrichment zone. According to the geochemistry analysis and some other geologic evidence of gas reservoir in the eastern-central part of the Ordos basin, this paper just discusses how to predict natural gas migration and favourable exploration areas using carbon isotopic fractionation information.

\section{REservolr Physical Properties AND NATURAL GAS GEOCHEMISTRY}

\section{A. Reservoir Physical Properties}

Shanxi formation of upper palaeozoic in the Ordos basin is mild and wet during depositional stage, with delta deposit well developed. Lithology is gray stone, dark gray stone, gray siltstone, mudstone and coal petrography. The coal seam and mudstone, with large thickness and steady distribution, are important source rocks of the study area. The main reservoirs are ditributary channel sand body of delta plain and delta front subfacies with mainly lower permeability feldspathic litharenite, feldspar quartz sandstone and lithic feldspar sandstone that shape thick layer, thin layer and lenticular and result in a bad lateral connectivity and anisotropy. Based on the analysis of 162 cores of Shanxi formation, we found that the sand body porosity is $6.0 \%$ to $10.0 \%$, with an average value $8.2 \%$; its permeability ranges from 0.3 to $0.5\left(10^{-3} \mu \mathrm{m}^{2}\right)$, with an average value $0.39\left(10^{-3} \mu \mathrm{m}^{2}\right)$.

The reservoir porosity of research area overall exhibits "north-east-south margin high, middle low" on the plane. The marginal porosity ranges from $8 \%$ to $10 \%$, with good continuity and a banding distribution; conversely, the middle and the west porosity are relatively low with a range of $3 \%$ to $7 \%$ and bad continuity.

\section{B. Natural Gas Geochemical Characteristics}

The gas component is mainly gas hydrocarbons including methane, ethane and propane, with a percentage scope of $93.7 \%$ to $99.87 \%$ ( sample number 27 ). Composition of the hydrocarbons is mainly methane averagely accounting for $91.55 \%$, with a basic frequency $96 \%$; the second is ethane with a composition percentage of $3.19 \%$ and a basic frequency $3.56 \%$; propane percentage and its basic frequency 
are the lowest, with the value of $0.61 \%$ and $0.49 \%$ respectively. According to the relative study results, different period coal-derived gas mixing is one of the reasons of above gas composition.

Gas carbon isotope $\delta^{13} C_{1}(\%), \delta^{13} C_{2}(\%)$ and $\delta^{13} C_{3}(\%$ )are distributed mainly in $-34.0 \sim-29.5,-25.0 \sim-22.2$ and $-24.0 \sim-22.6$, and their mean value are -32.7 (sample number:36), -24.6 and -24.2 (sample number:27), respectively.

\section{CARBON ISOTOPIC FRACTIONATION AND NATURAL GAS PREDICTION}

Natural gas carbon isotopic fractionation effect occurs mainly during the process of hydrocarbon generation from source rock and of oil/gas migration. Lighter ${ }^{12} \mathrm{C}$ hydrocarbons generate first because ${ }^{12} C-{ }^{12} C$ bond is weaker than ${ }^{12} \mathrm{C}-{ }^{13} \mathrm{C}$ bond in the course of hydrocarbon generation. Thus carbon isotope becomes heavier gradually with later increased maturity. Natural gas migration pattern manifests as transport dispersion and percolation migration, and the two patterns both make for carbon isotopic fractionation effect. Consequently, $\delta^{13} C$ is more negative in the front of gas migration direction because ${ }^{13} C$ is absorbed more easily than ${ }^{12} \mathrm{C}$.

The natural gas reservoir of upper palaeozoic belongs to self-generating and self-preserving tight sandstone gas, and it is affected little by late geological reformation, as a result that carbon isotope information in the reservoir retains the state of primary hydrocarbon generation and natural gas migration. So we could analyze natural gas migration using the retained carbon isotope information, and predict favorable natural gas reservoir combining with sand body physical characteristics.

Based on the understanding of the gas reservoir that belongs to self-generating and self-preserving tight sandstone gas, we can identify local hydrocarbon generation center and relative lower permeability zone, and predict the direction of natural gas migration by distribution of $\delta^{13} C_{1}$ isotope. From the horizontal distribution of methane carbon isotope in Fig. 1, we can plot out three hydrocarbon generation centers and two local lower permeability zones. $\delta^{13} C_{1}$ value in local hydrocarbon generation center is higher than those in external, and it is generally greater than $-31 \%$; while the condition in local lower permeability zone is opposite with higher $\delta^{13} C_{1}$ in external zone and lower in center. $\delta^{13} C_{1}$ isoline between local hydrocarbon generation center and local lower permeability zone is dense, and it indicates boundary between lower permeability zone and local hydrocarbon generation center; while $\delta^{13} C_{1}$ isoline in sparse region indicates the main direction of natural gas migration. So we can estimate that the gas migrated roughly along both Hengshan-Wushenqi and Zizhou-Jiaxian directions from south to north. $\delta^{13} C_{1}$ sparse isoline region centered on Wushenqi forms the most favorable gas pool, and analogically, favorable gas pools could come into being in the north of Jiaxian and south of Hengshan closed to the gas sources.

Sand body thickness, porosity and permeability are important indexes to evaluate reservoir. Sand body thickness and porosity provide necessary storage space for gas; while permeability is the main index that controls natural gas migration and crucial factor of gas well production. Because of the limitation of single indicator of reservoir, and quality of reservoir having positive relations with above three indexes, the paper defines storage index(D) to evaluate the reservoir of upper palaeozoic in the eastern-central part of the Ordos basin, that is index(D) = sand body thickness(M) $\times \operatorname{porosity}(\varphi) \times$ permeability $(\mathrm{K})$. Fig. 2 is the evaluation result on study area reservoir using the index to explore favorable zone. We plot out three favorable exploration zones: the southeast of Wushenqi that is ' $S$ ' distribution along north-south, west of Shenmu, and west of Jiaxian along north-south. Combined with Fig. 1 results, namely hydrocarbon generation centers and natural gas migration directions by isotope, it is concluded that Wushenqi is the most favorable exploration zone, and the second is Jiaxian zone. Although Shenmu area is beneficial to store gas, none favorable hydrocarbon generation center around could be found in accordance with the isotope result (Fig. 1), so further study is necessary.

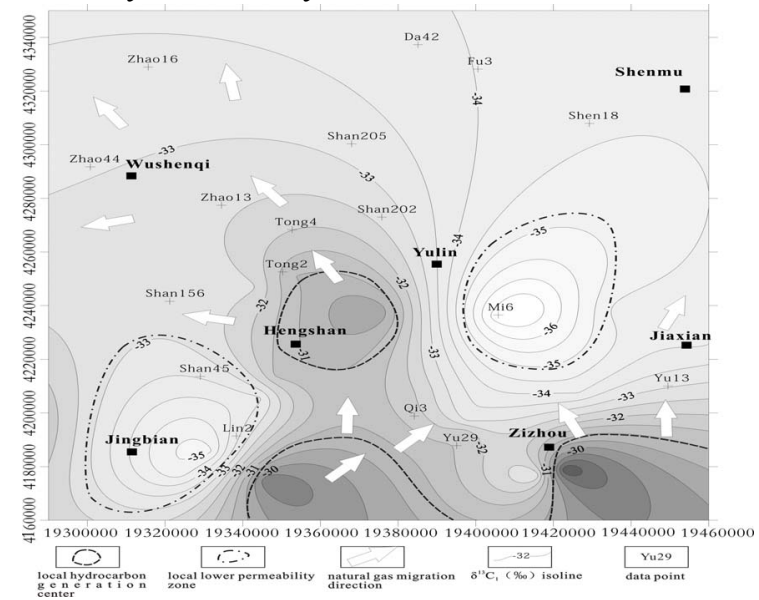

Fig. 1. Relationship of me thane carbon isotopic fractionation $\left(\delta^{13} \mathrm{C}_{1}\right)$ and natural gas migration of Shanxi formation, upper palaeozoic in the eastern-center of the Ordos basin

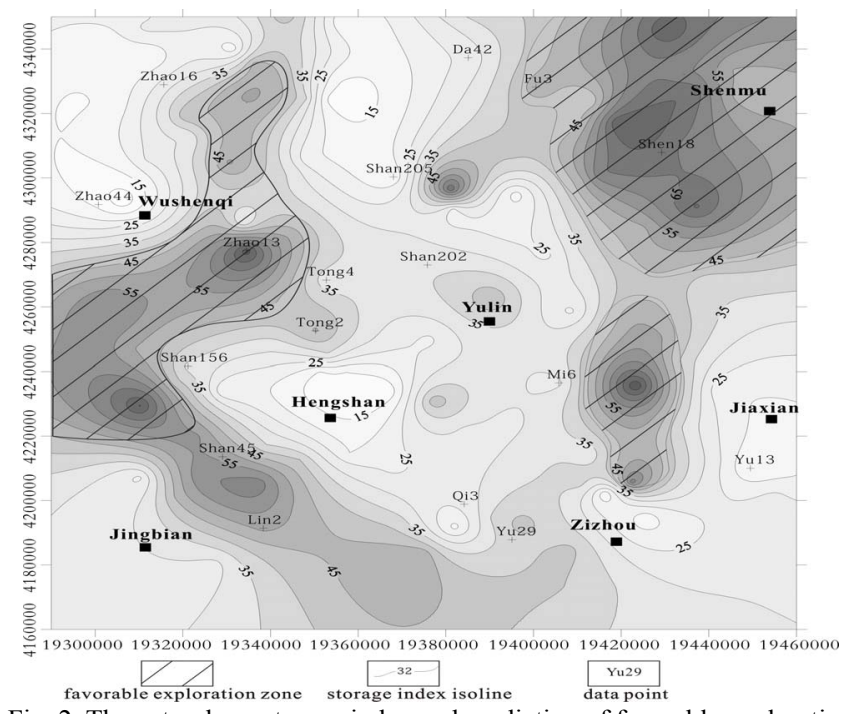

Fig. 2. The natural gas storage index and prediction of favorable exploration area of Shanxi formation, upper palaeozoic in the eastern-center of the Ordos basin

\section{DisCUSSIONS AND CONCLUSIONS}

In this paper, we discussed how to choose favorable 
exploration area with combination of organic carbon isotopic fractionation and reservoir physical indexes taking example of Shanxi formation, upper palaeozoic in the eastern-central part of the Ordos basin. For Self-generating and self-preserving tight sand gas reservoir, the method is feasible according to the study, partially because of the weakly geological transformation. But for the conventional gas reservoirs such as fault-traped, anticlinal, and salt dome reservoirs and the like, the method loses elementary conditions, mostly because the reservoir and the gas pool are far from the source and migration channel was changed many times by strongly geological transformation. Thus the recorded carbon isotope information in the gas reservoir could not reflect hydrocarbon-expulsion state, although it could reflect gas migration direction partly. Finally, from this study the following conclusions can be drawn:

1) In the gas reservoir, relatively high $\delta^{13} C_{1}$ value region indicates local hydrocarbon generation center, and $\delta^{13} C_{1}$ value decreases from the center to external zone; lower $\delta^{13} C_{1}$ value region indicates relatively lower permeability zone.

2 ) In the same gas system, Density of $\delta^{13} C_{1}$ isoline reflects permeability partly. Permeability is lower in dense area of $\delta^{13} \mathrm{C}_{1}$ isoline and higher in sparse area.

3) For tight sandstone gas reservoir, gas migration direction and favorable exploration area could be predicted effectively with combination of gas carbon isotope and the storage index.

In the figure, the dark grey areas show that the $\delta^{13} C_{1}$ value is higher, indicating higher maturity or hydrocarbon-generating center. In contrary, the shallow grey areas show that the $\delta^{13} \mathrm{C}_{1}$ value is lower, indicating lower permeable area. So the negative gradient of the isoline denotes the gas migration direction, that is the gas migrating from dark grey area to shallow area; and that the denser isoline means lower permeability, and the sparser means higher permeability.

The storage index in this paper expresses the reservoir quality with porosity, permeability and thickness. In the figure, the dark grey area corresponds to the sparser-isoline area in Fig. 1 approximately, verifying the reliability of methane carbon isotopic fractionation $\left(\delta^{13} \mathrm{C}_{1}\right)$ indicating some reservoir characteristics.

\section{REFERENCES}

[1] U. Bener, E. Faber, and W. Stahl, "Mathematical simulation of the carbon isotopic fractionation between huminitic coals and related methane," Chemical Geology, vol. 94, no. 4, pp. 315-319, 1992.

[2] F. Lorant, F. Behar, and M. Vandenbroucke, "Methane generation from methylated aromatics: Kinetic study and carbon isotope modeling," Energy and Fuels, vol. 14, pp. 1143-1155, 2000.

[3] H. X. Lin, F. Q. Cheng, and Q. Jin, "Fractionation Mechanism of Natural Gas Components and Isotopic Compositions and Sample Analysis," Natural gas geoscience, vol. 22, no. 2, pp. 195-200, 2011.

[4] Y. H. Shuai, Y. R. Zou, J. Z. Liu et al., "Carbon Isotope Modeling of Coal-der ived Methane and Ethane from the Upper Paleozoic of the Ordos Basin, China," Geological review, vol. 51, no. 6, pp. 665-671, 2005.

[5] Y. H. Liao, A. S. Geng, D. H. Liu et al., "Carbon isotopic fractionation effect caused by maturity during the generationof coal - pyrolysis hydrocarbons," Petroleum geology \& experiment, vol. 29, no. 6, pp. 583-588, 2007.

[6] M. A. Rooney, "Modeling thermogenic gas generaion using carbon isotope ratios of natural gas hydrocarbons," Chemical Geology, vol. 126, pp. 219-232, 1995.

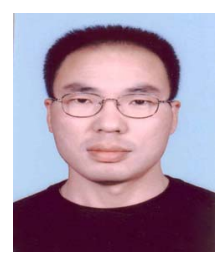

Yun-Feng Zhang is currently studying at the China University of Geosciences (Beijing) for a doctorate in Energy Geological Engineering, is mainly engaged in the research work of deposition system, geochemistry and fluid potential. 